\title{
Interferon-Combination Strategies for the Treatment of Chronic Hepatitis C
}

\author{
Andrew Aronsohn, $\mathrm{MD}^{1} \quad$ Donald Jensen, $\mathrm{MD}^{1}$ \\ ${ }^{1}$ Center for Liver Disease, Section of Gastroenterology, Hepatology \\ and Nutrition, University of Chicago Medical Center, Chicago, Illinois \\ Semin Liver Dis 2014;34:30-36. \\ Address for correspondence Andrew Aronsohn, MD, Center for Liver \\ Disease, Section of Gastroenterology, Hepatology and Nutrition, 5841 \\ South Maryland Avenue, MC 7120, Chicago, IL 60637 \\ (e-mail: aaronsoh@medicine.bsd.uchicago.edu).
}

Abstract
Keywords
- hepatitis $C$
- hepatitis $C$ therapy
- direct-acting antiviral
agents

Direct acting antiviral agents have revolutionized hepatitis C (HCV) therapy. Many agents that are either currently available or undergoing investigation offer higher rates of sustained virologic response, reduced toxicity and shorter duration of therapy when compared to traditional treatment consisting of pegylated interferon and ribavirin. Although interferon free therapy may be a preferred option, some patients may still require an interferon based regimen to ensure efficacy. In this review, we discuss therapeutic strategies which utilize various combinations of protease inhibitors, NS5A inhibitors, nucleotide polymerase inhibitors and non-nucleoside polymerase inhibitors along with pegylated interferon in the treatment of chronic HCV.
In 2011, the first direct-acting antiviral agents (DAAs) became available for use in the treatment of chronic hepatitis $C$. In large registration trials, the addition of either telaprevir or boceprevir to peginterferon (PegIFN) and ribavirin (RBV) increased sustained virologic response rates and for many patients allowed for shortened duration of therapy. ${ }^{1,2}$ Since approval, multicenter postmarketing studies have shown that treatment with first-generation DAAs have resulted in somewhat lower than expected response rates and a relatively high frequency of adverse events while on therapy. ${ }^{3}$ Upcoming generations of DAAs offer promise of improved efficacy with limited toxicity. Although the ultimate goal in hepatitis $C$ virus (HCV) treatment is simple and effective IFN-free therapy, many second-wave DAAs will still require interferon to achieve acceptable response rates. In this review, we will discuss novel HCV treatment regimens where interferon is combined with the next generation of DAAs [ - Table 1].

\section{Protease Inhibitors}

During the HCV life cycle, the NS3 protease binds to its NS4A cofactor and plays a key role in the posttranslational processing of the HCV polyprotein. ${ }^{4}$ Protease inhibitors (PIs) block the catalytic function of the NS3/4A protease, and halt virus production by preventing mature nonstructural viral proteins to be generated. In addition, because the NS3/4A complex is involved in decreasing activity of type 1 IFN though cleavage of IFN-B promoter stimulator-1 (IPS-1), blockage of this complex formation is also thought to stimulate innate immune response. ${ }^{5}$ Second-wave, first-generation PIs have improved dosing schedules and more tolerable sideeffect profiles when compared with telaprevir and boceprevir. Beyond the second-wave PIs, second-generation PIs are expected to have broader genotypic coverage and higher barriers to resistance. ${ }^{6}$

\section{Simeprevir}

Simeprevir (TMC 435) is a potent, second-wave, first-generation NS3/4A PI with antiviral activity in genotypes 1, 2, 4, 5 , and 6. The U.S. Food and Drug Administration (FDA) has approved this agent as part of combination therapy for treatment-experienced and treatment-naïve genotype 1 patients. In QUEST 1, a randomized, double-blind placebo controlled trial of treatment naïve patients, response-guided therapy using simeprevir $150 \mathrm{mg}$ daily was administered for 12 weeks combined with PegIFN/RBV for 24 to 48 weeks. Overall, simeprevir-based therapy yielded sustained virologic response (SVR) rates of $80 \%$ compared with $50 \%$ in patients treated with PegIFN/RBV dual therapy. In this study, 224 of 264 patients (85\%) met criteria for response-guided therapy and were able to shorten duration of treatment to 24 weeks. Among patients treated with simeprevir, those with
Issue Theme New Hepatitis C Therapies; Guest Editor, Jean-Michel Pawlotsky, MD, $\mathrm{PhD}$
Copyright (C) 2014 by Thieme Medical Publishers, Inc., 333 Seventh Avenue, New York, NY 10001, USA. Tel: +1(212) 584-4662.
DOI http://dx.doi.org/ 10.1055/s-0034-1371008. ISSN 0272-8087. 
Table 1 Summary of novel DAA/interferon containing HCV regimens

\begin{tabular}{|c|c|c|c|c|}
\hline Agent & Class & Genotype & Previous treatment & Treatment outcome (SVR) \\
\hline \multirow[t]{2}{*}{ Simeprevir } & \multirow[t]{2}{*}{$\mathrm{NS3} / 4 \mathrm{~A} \mathrm{PI}$} & \multirow[t]{2}{*}{1,4} & Naïve & $\begin{array}{l}\text { - QUEST 1: } 80 \% \\
\text { - QUEST 2: } 81 \%\end{array}$ \\
\hline & & & Experienced & $\begin{array}{l}\text { - ASPIRE: } \\
\text { Null: } 38-59 \% \\
\text { Partial response: } 48-86 \% \\
\text { Relapse: } 77-89 \%\end{array}$ \\
\hline MK-5172 & $\mathrm{NS3} / 4 \mathrm{~A} \mathrm{PI}$ & 1 & Naïve & $86-91 \%$ \\
\hline Asunaprevir & NS3/4A PI & 1,4 & Naïve & $\begin{array}{l}\text { - G1: } 64 \% \\
\text { - G4: } 89 \%\end{array}$ \\
\hline \multirow[t]{2}{*}{ Faldaprevir } & \multirow[t]{2}{*}{$\mathrm{NS3} / 4 \mathrm{~A} \mathrm{PI}$} & \multirow[t]{2}{*}{1} & Naïve & $\begin{array}{l}\text { - SILEN-C1: } 72-84 \% \\
\text { - STARTVerso } 1 / 2: 60-88 \%\end{array}$ \\
\hline & & & Experienced & $\begin{array}{l}\text { - SILEN-C2: } \\
\text { Null: } 21-29 \% \\
\text { Partial response: } 32-50 \% \\
\text { - STARTVerso 3: } \\
\text { Null:33\% } \\
\text { Partial response: } 47-58 \% \\
\text { Relapse: } 70 \%\end{array}$ \\
\hline \multirow[t]{2}{*}{ Daclatasvir } & \multirow[t]{2}{*}{ NS5A inhibitor } & 1,4 & Naive & $\begin{array}{l}\text { - COMMAND 1: } \\
\text { G1: } 58-87 \% \\
\text { G4: } 100 \%\end{array}$ \\
\hline & & 2,3 & Naïve & $\begin{array}{l}\text { - COMMAND GT } 2 / 3 \\
\text { G2: } 83 \% \\
\text { G3: } 67-69 \%\end{array}$ \\
\hline Setrobuvir & NNPI & 1 & Naïve & Unavailable \\
\hline Deleobuvir & NNPI & 1 & Naïve & Unavailable \\
\hline Sofosbuvir & NPI & $1,4,5,6$ & Naïve & $\begin{array}{l}\text { - ATOMIC: } 87-89 \% \\
\text { - NEUTRINO: } \\
\text { G1: } 82-92 \% \\
\text { G4:100\% } \\
\text { G5: } 100 \%(n=1) \\
\text { G6: } 100 \%(n=6)\end{array}$ \\
\hline Mericitabine & NPI & 1,4 & Naïve & $\begin{array}{l}\text { - PROPEL: } 33-51 \% \\
\text { - JUMP-C: } 57 \%\end{array}$ \\
\hline Mericitabine/ Danoprevir (QUAD) & $\mathrm{NPI} / \mathrm{PI}$ & 1 & Experienced & $\begin{array}{l}\text { - MATTERHORN } \\
\text { Null: } 100 \% \\
\text { Partial responder: } 96 \%\end{array}$ \\
\hline $\begin{array}{l}\text { Asunaprevir/ } \\
\text { Daclatasvir (QUAD) }\end{array}$ & $\mathrm{PI} / \mathrm{NS} 5 \mathrm{~A}$ inhibitor & 1 & Experienced & Null: $90-100 \%$ \\
\hline $\begin{array}{l}\text { VX222/Telaprevir } \\
\text { (QUAD) }\end{array}$ & NNPI/PI & 1 & Naïve & • ZENITH: 82-93\% \\
\hline $\begin{array}{l}\text { Tegobuvir/GS9451 } \\
\text { (QUAD) }\end{array}$ & $\mathrm{NNPI} / \mathrm{PI}$ & 1 & Naïve & $\begin{array}{l}\text { G1a: } 74 \% \\
\text { G1b: } 90 \%\end{array}$ \\
\hline
\end{tabular}

Abbreviations: DAA, direct-acting antiviral agent; HCV, hepatitis C virus; NPI, nucleotide polymerase inhibitor; NNPI, nonnucleoside polymerase inhibitor; PI, protease inhibitor.

unfavorable IL28B genotype, advanced fibrosis, and genotype 1a had inferior response rates. ${ }^{7}$ Notably, because the presence of a pre-existing Q80K mutation has been shown to significantly reduce response rates, the simeprevir package insert recommends screening patients with genotype $1 \mathrm{a}$ HCV for this mutation, and if present, consideration of alternative therapy. ${ }^{8}$

The QUEST 2 trial was a similar randomized, double-blind, placebo controlled trial in treatment-naïve genotype 1 pa- tients, which evaluated impact of type of IFN on response rates (PegIFN- $\alpha-2 a$ vs. PegIFN- $\alpha-2 b$ ). In this trial, 209 of 257 patients (81\%) treated with simeprevir achieved SVR with $91 \%$ eligible for truncated therapy of 24 weeks. The type of interferon used did not affect response rates. In addition, HCV subtype was not found to be a predictor of SVR in this study (80\% SVR12 in genotype 1a vs. $82 \%$ SVR12 in genotype $1 \mathrm{~b}$ ). Lower SVR rates were again seen in patients with advanced fibrosis (SVR12: 65-67\%); however, these remained 
significantly higher when compared with PegIFN/RBV control arms (SVR12: 40-53\%). ${ }^{9}$

Previous nonresponders to PegIFN/RBV dual therapy were treated with simeprevir and evaluated in the phase IIb ASPIRE trial. Patients in experimental arms were treated with simeprevir (100 mg or $150 \mathrm{mg}$ daily) for 12,24 , or 48 weeks plus PegIFN/RBV for 48 weeks. Higher SVR rates were seen in all simeprevir-containing arms when compared with PegIFN/ RBV-treated controls (SVR24 rates: prior null response 38$59 \%$ vs. $19 \%$; prior partial response $48-86 \%$ vs. $9 \%$; prior relapse; $77-89 \%$ vs. $37 \%)^{10}$

Overall simeprevir was well tolerated and adverse events in experimental arms were similar to PegIFN/RBV plus placebo arms. In QUEST 1, the most common adverse events included fatigue, headache, and pruritus. In simeprevir arms, transient mild bilirubin elevations were also noted, which are attributed to inhibition of OATP1B1/MRP2 transporters. In this study, adverse events led to treatment discontinuation in $3 \%$ of patients. ${ }^{7}$

\section{MK 5172}

MK 5172 is a second-generation macrocyclic, NS3/4A PI that has been shown to have pan-genotypic antiviral activity and to exhibit higher potency to common protease-resistant variants R155K and D168Y than first-generation compounds. ${ }^{11}$ In an ongoing phase 2 study, noncirrhotic genotype 1 patients were randomized to receive MK 5172 for 12 weeks at various dosages along with PegIFN/RBV for 24 to 48 weeks. Experimental arms were compared with a control group consisting of patients receiving boceprevir/PegIFN/RBV. SVR24 rates were $86 \%$ (100 mg MK-5172), 92\% (200 mg MK-5172), 91\% (400 mg MK 5172), and 87\% (800 mg MK 5172) compared with 54\% achieving SVR24 in boceprevir containing arms. ${ }^{12}$ Among patients treated at the $100 \mathrm{mg}$ dosage, 60 of 66 patients (91\%) were eligible for truncation of therapy to 24 weeks, of which $98 \%$ achieved SVR. Patients with genotype $1 \mathrm{a} \mathrm{HCV}$ had lower response rates ( $81 \%$ genotype 1 a vs. $96 \%$ genotype non-1a); however, of the genotype 1a patients who did not achieve SVR, no baseline resistant variants were found. Overall, MK 5172 was better tolerated than boceprevir with lower rates of rash, anemia, and treatment discontinuation due to an adverse event. Elevations in both aminotransferases and bilirubin occurred in patients treated with MK 5172; however, this was predominantly noted at the higher dose ranges. ${ }^{12}$

\section{Asunaprevir}

Asunaprevir (BMS 650032) is a second-wave, first-generation macrocyclic, selective NS3 PI with in vitro activity against HCV genotypes 1, 4, 5, and 6. In phase 2a study, asunaprevir was given in combination with PegIFN/RBV at doses ranging from $400 \mathrm{mg} / \mathrm{d}$ to $1200 \mathrm{mg} / \mathrm{d}$. SVR24 rates were significantly higher than in the PegIFN/RBV group (SVR24: $83-92 \%$ vs. $46 \%$ ); however, at 12 -week analysis, greater frequency of aminotransferase elevations were seen at higher doses and all dosages were decreased to $200 \mathrm{mg}$ twice daily. ${ }^{13}$ In phase $2 \mathrm{~b}$ study, treatment duration and efficacy was evaluated in patients with genotype 1 and 4 . Patients received asunaprevir
$200 \mathrm{mg}$ twice daily for 12 to 24 weeks combined with PegIFN/ RBV for 24 to 48 weeks and were compared with patients receiving PegIFN/RBV dual therapy. ${ }^{14}$ In intention-to-treat analysis, $64 \%$ of genotype 1 patients treated with asunaprevir containing regimens achieved SVR24 compared with $45 \%$ in control arms. In genotype 4 patients, SVR24 was seen in 15 of 17 patients (89\%) of patients receiving asunaprevir compared with $43 \%$ (3/7) treated with PegIFN/RBV. ${ }^{14}$ At the $200 \mathrm{mg}$ twice daily dosage, asunaprevir was generally well tolerated; however, grade 3 to 4 aminotransferase elevations were more frequent in experimental arms (10\% vs. $2 \%$ ). All aminotransferase elevations resolved and none met predetermined Dry Induced Liver Injury (pDILI) criteria. ${ }^{14}$

\section{Faldaprevir}

Faldaprevir is a second-wave, first-generation NS3/4A PI with a relatively long half-life, enabling daily dosing. In the phase $2 \mathrm{~b}$ study SILEN-C1, treatment-naïve, genotype 1 noncirrhotic patients were randomized to receive 24 weeks of PegIFN/RBV combined with faldaprevir $120 \mathrm{mg}$ with a 3-day PegIFN/PBV lead-in, $240 \mathrm{mg}$ daily with a 3-day lead-in, or $240 \mathrm{mg}$ daily without lead-in followed by 24 weeks of PegIFN/RBV. ${ }^{15}$ Patients in the $240 \mathrm{mg}$ with group who maintained rapid virologic response (mRVR) were randomized to 24 or 48 weeks of total treatment duration. Overall, SVR was achieved in 72 to $84 \%$ of patients treated with faldaprevir compared with $56 \%$ in the placebo arm. The majority of patients (78-87\%) treated with $240 \mathrm{mg}$ faldaprevir achieved mRVR; however, lower SVR rates ( $81 \%$ vs. $96 \% p=0.051$ ) and higher relapse rates ( $17 \%$ vs. $4 \%$ ) were seen in patients who underwent 24 weeks of total therapy. ${ }^{15}$

In SILENC-2, prior null responders and partial responders to PegIFN/RBV therapy were treated with faldaprevir-containing regimens. Patients were treated with 48 weeks of PegIFN/RBV in combination with faldaprevir $240 \mathrm{mg}$ once daily with a 3-day lead-in of PegIFN/RBV dual therapy, $240 \mathrm{mg}$ daily without lead-in, or $240 \mathrm{mg}$ twice daily with lead-in. In prior partial responders, SVR rates were $32 \%, 50 \%$, and $42 \%$; in prior null responders, SVR rates were $21 \%, 35 \%$, and $29 \%$ in the faldaprevir $240 \mathrm{mg}$ daily/lead-in, $240 \mathrm{mg}$ daily, and $240 \mathrm{mg}$ twice daily/lead-in groups, respectively. Patients with mRVR were eligible for 24 weeks of therapy; however, similar to SILENC-1, patients treated with truncated duration of therapy had inferior response rates (SVR: $72 \%$ vs. $43 \% ; p=0.035){ }^{16}$

In the phase III trials STARTVerso 1 and 2, 1309 genotype 1 treatment naïve patients from Europe, Asia, and North America were treated with either faldaprevir $120 \mathrm{mg}$ or $240 \mathrm{mg}$ daily for 12 to 24 weeks along with PegIFN/RBV for 24 to 48 weeks. SVR12 rates ranged from $60 \%$ to $88 \%$ and were noted to be highest in Asian cohorts. ${ }^{17}$ In STARTVerso 3, 677 prior nonresponders were treated with faldaprevir $240 \mathrm{mg}$ for 12 to 24 weeks along with PegIFN/RBV for 48 weeks. SVR12 rates for patients with prior relapse (70\%), partial response (47-58\%), and null response (33\%) were all significantly higher than PegIFN/RBV control. Of note, relatively low response rates (13-18\%) were seen in prior null responders with cirrhosis. ${ }^{18}$ Finally, in STARTVerso 4, patients with HCV/ 
HIV coinfection were studied. Patients received faldaprevir 120-240 mg daily plus PegIFN/RBV with an overall SVR4 rate of $74 \%{ }^{19}$

Faldeprevir was well tolerated and within the Phase III STARTVerso trials, discontinuation due to adverse events ranged from $4-7 \%$. More common adverse events included increased in bilirubin and phototoxicity.

\section{NS5A Inhibitors}

NS5A is a 447 amino acid protein that plays a key role in HCV viral replication and viral particle assembly. Inhibition of this protein by novel therapeutic agents has been shown to block RNA replication by effectively disrupting the assembly of the $\mathrm{HCV}$ replication complex. ${ }^{20}$

\section{Daclatasvir}

Daclatasvir is a potent, first-in-class NS5A inhibitor that has been shown to have pan-genotypic activity. ${ }^{21}$ In COMMAND GT 2/3, patients with HCV genotypes 2 and 3 were treated with daclatasvir $60 \mathrm{mg}$ daily in addition to PegIFN/RBV for either 12 or 16 weeks and were compared with a control group receiving PegIFN/RBV for 24 weeks. Numerically higher SVR24 rates were seen in both genotypes in patients who received daclatasvir (genotype 2 : SVR2 $4=83 \%$ vs. $63 \%$ and genotype 3 SVR24=67-69\% vs. 59\%). ${ }^{22}$ In COMMAND-1, patients with genotype $1(n=365)$ and $4(n=30)$ were treated with daclatasvir/PegIFN/RBV regimens. In this study, patients were randomized to receive either $20 \mathrm{mg}$ or $60 \mathrm{mg}$ of daclatasvir for 12 to 24 weeks in combination with PegIFN/ RBV for 24 weeks. Among genotype 1 patients treated with daclatasvir $60 \mathrm{mg}$, SVR12 rates for genotype 1b (87\%) were higher than in patients with genotype 1a (58\%). This difference is thought to be due to a fivefold higher antiviral potency and a higher genetic barrier to resistance in genotype $1 \mathrm{~b}$. Among those with genotype $4 \mathrm{HCV}$, patients receiving daclatasvir $60 \mathrm{mg}$ had a $100 \%$ SVR rate (12 of 12 ) compared with PegIFN/RBV control arms with a 50\% SVR rate (3 of 6 patients). Overall, adverse-event profiles in daclatasvir arms were similar to patients treated with PegIFN/RBV dual therapy with the exception of dry skin, influenza-like illness, and nausea, which were seen more frequently ( $>10 \%)$ in experimental arms. ${ }^{23}$

\section{Nonnucleoside Polymerase Inhibitors}

Nonnucleoside polymerase inhibitors (NNPIs) act as allosteric inhibitors of the RNA-dependent RNA polymerase (NS5B) that catalyzes viral replication. This enzyme has four allosteric binding sites that are potential targets for NNPIs: thumb domain 1 and 2 and palm domain 1 and 2. NNPIs have efficacy in genotype $1 \mathrm{HCV}$ only and when used without other DAAs have a low barrier to resistance. ${ }^{24}$

\section{Setrobuvir}

Setrobuvir is a well-tolerated, NNPI that inhibits the palm 1 domain of the NS5B RNA polymerase. In a phase II study, patients received setrobuvir or placebo with PegIFN/RBV for
12 weeks at $200 \mathrm{mg}$ twice daily or $400 \mathrm{mg}$ twice daily, both given with a loading dose of $800 \mathrm{mg}$ every 12 hours on day 1 . Those with an undetectable viral load at weeks 4 and 12 were randomized to receive PegIFN/RBV dual therapy for an additional 12 or 36 weeks. Early viral kinetics of setrobuvir arms were superior to PegIFN/RBV arms. ${ }^{25}$ In this study, adverse events in setrobuvir containing arms were similar to controls with the exception of one patient who discontinued setrobuvir due to a grade 3 rash. Because of high rates of relapse, an additional phase II study has recently been completed in which setrobuvir was given for a longer duration in both treatment naïve and treatment experienced patients. Results from this trial are pending. ${ }^{26}$

\section{Deleobuvir}

Deleobuvir is a NNPI that targets the thumb domain 1 and has been studied in combination with PegIFN/RBV in phase Ib trials. The majority of investigation of this drug has been part of IFN-free regimens with the PI faldaprevir. ${ }^{27}$ In a phase $1 \mathrm{~b}$, double-blind placebo controlled dose-finding study, both treatment-naïve $(n=27)$ and treatment-experienced patients $(n=30)$ were treated with deleobuvir at 400,600 , or $800 \mathrm{mg}$ three times daily dosing. Rapid virologic response rates at day 28 were seen in 11 of 19 treatment-naïve patients and 4 of 30 treatment-experienced patients. Higher response rates were seen on genotype $1 \mathrm{~b}$ patients. Overall, the $600-\mathrm{mg}$ dosing was found to have the optimal benefit/risk ratio. Three previous nonresponders experienced viral breakthrough while on treatment, all of which developed resistance via an amino acid substitution at P495; however, by the end of follow-up, all patients reverted to wild-type virus. Gastrointestinal and rash/photosensitivity were more common in deleobuvir-containing arms when compared with placebo. ${ }^{28}$

\section{Nucleotide Polymerase Inhibitors}

Once phosphorylated, nucleoside or nucleotide analog PIs compete with viral nucleotides during RNA chain elongation and when incorporated, result in chain termination, thereby halting the HCV life cycle. Nucleoside/nucleotide analog polymerase inhibitors have a pan-genotypic coverage and a high barrier to resistance due to the very poor replication capacity of the HCV variants they select.

\section{Sofosbuvir}

Sofosbuvir acts as a chain terminator within the catalytic site of the NS5B polymerase. It has been approved by the FDA for treatment of genotype 1, 4, 5, and 6 along with PegIFN /RBV and in genotype 2 and 3 patients as an IFN-free regimen with ribavirin only.

Phase 2 studies of sofosbuvir (400 mg daily) plus PegIFN/ RBV for 12 to 24 weeks resulted in SVR rates ranging from 87 to $92 \%{ }^{29,30}$ In ATOMIC, an open label, randomized, multicenter phase 2 trial, 316 genotype 1 patients were randomized to receive sofosbuvir $400 \mathrm{mg}$ plus PegIFN/RBV for 12 weeks (cohort A) sofosbuvir plus PegIFN/RBV for 24 weeks (cohort B), or 12 weeks of sofosbuvir plus PegIFN/RBV followed by 12 weeks of either sofosbuvir monotherapy or sofosbuvir plus 
ribavirin (cohort $\mathrm{C}$ ). High response rates were seen in all cohorts (SVR24: cohort $A=89 \%$, cohort $B=89 \%$, cohort $\mathrm{C}=87 \%) .{ }^{29}$ NEUTRINO is a single group, open-label phase 3 study of treatment-naive genotype 1, 4, 5 and 6 patients who were treated for 12 weeks with sofosbuvir plus PegIFN/ RBV. ${ }^{31}$ The overall SVR12 rate was $90 \%$ and similar response rates were seen regardless of genotype (SVR12: 92\% for genotype $1 \mathrm{a}, n=225$; $82 \%$ for genotype $1 \mathrm{~b}, n=66$; $96 \%$ for genotype $4, n=28 ; 100 \%$ for genotype $5, n=1 ; 100 \%$ for genotype $6, n=6)$. In multivariate analysis, non-CC IL28B genotype (SVR 12: $87 \%$ vs. $98 \%$ ) and cirrhosis (80\% vs. $92 \%$ ) were significantly associated with reduced response. Among patients enrolled in NEUTRINO, 28 patients received sofosbuvir and had a relapse after initial virologic response at the end of treatment. Posttreatment deep-sequencing analysis was performed, which showed no resistance-associated variants. $^{31}$

Overall, sofosbuvir is well tolerated. In NEUTRINO, there was a $2 \%$ discontinuation rate due to adverse events in sofosbuvir-containing arms with low overall rates of severe adverse events. $^{31}$

\section{Mericitabine}

Mericitabine is a selective nucleoside analog inhibitor of the NS5B RNA polymerase. In PROPEL, treatment-naïve genotype 1 or 4 patients received mericitabine $500 \mathrm{mg}$ twice daily for 12 weeks (Arm A), 1,000 mg BID for 8 weeks (Arm B) or $1000 \mathrm{mg}$ BID 12 weeks (Arms C and D), or placebo (Arm E) in addition to PegIFN/RBV. Patients in arms $A$ to $C$ were able to truncate therapy to 24 weeks if they maintained a viral response from week 4 to 22. All other patients received PegIFN/RBV for 48 weeks. Although viral kinetics at week 4 and 12 were superior to placebo, overall SVR24 rates were similar or lower than placebo (Arm $A=48.8 \%, A r m B=42 \%$, $\operatorname{Arm} C=32.9 \%$, Arm D $=50.6 \%$, and Arm $E=51.2 \%$ ). Investigators concluded that longer duration of mericitabine therapy was needed. ${ }^{32}$ In JUMP-C, a longer duration of mericitabine was given as $1000 \mathrm{mg}$ twice daily for 24 weeks, along with PegIFN/RBV. In this study, patients who achieved virologic response at weeks 4 and 22 were also eligible for response-guided therapy and stopped all treatment at week 24 . All other patients received 48 weeks of therapy. Overall, SVR24 was achieved in 56.8\% in mericitabine-treated patients as compared with $36.5 \%$ of dual therapy controls. In addition, relatively high relapse rates $(27.7 \%)$ were seen in patients treated with mericitabine. Of 30 patients who met criteria for resistance monitoring, the S282T mutation was not detected in any samples. Mericitabine was well tolerated as all adverse events seen were typical for PegIFN/ RBV therapy and no specific safety concerns were identified. $^{33}$

\section{QUAD Therapy}

Various manufacturers have combined two classes of DAAs with PegIFN/RBV in an effort to create highly potent and shorter-duration treatment regimens that could potentially be effective in difficult to treat populations.

\section{Mericitabine/Danoprevir/PegIFN/RBV}

Due to a relatively low response rate in mericitabine-containing triple therapy, the MATTERHORN study investigated the combination of mericitabine and ritonavir-boosted danoprevir, a second-wave, first-generation PI, along with PegIFN/RBV as QUAD therapy. Triple therapy of ritonavir/ danoprevir with PegIFN and RBV for 24 weeks was administered to genotype 1 patients with prior partial response, yielding an SVR12 rate of 56\%. Patients who received this regimen plus the addition of mericitabine were noted to have increased the SVR12 rate to $86 \%$. Among treatment-experienced patients with genotype $1 \mathrm{~b}$ infection, QUAD therapy resulted in an SVR12 rate of $96 \%$ in prior partial responders and $100 \%$ in null responders. A 73\% SVR12 rate was seen on patients with genotype $1 \mathrm{a}$ who were prior null responders. Of patients with either virologic breakthrough or relapse, resistant mutations were associated with danoprevir only (predominantly R155K). This regimen was well tolerated and of the 127 patients who received this QUAD therapy, five reported one or more serious adverse events and three patients discontinued therapy due to any adverse event ${ }^{34}$ In lieu of danoprevir, QUAD therapy containing mericitabine, PegIFN/RBV, and either telaprevir or boceprevir are also under investigation. ${ }^{35,36}$

\section{Asunaprevir/Daclatasvir/PegIFN/RBV}

Although both asunaprevir and daclatasvir are potential candidates for effective IFN-free regimens, the combination of these agents along with PegIFN/RBV has been investigated as therapy for difficult to treat genotype 1 null responders. ${ }^{37}$ In 2012, Lok presented results of 41 patients treated with asunaprevir based QUAD therapy. Patients were randomized to receive daclatasvir $60 \mathrm{mg}$ QD plus PegIFN/RBV and asunaprevir at either $200 \mathrm{mg}$ daily or twice daily. Notably, the majority of patients enrolled were genotype 1a (88\%). Both QUAD therapy arms were treated for 24 weeks and resulted in high response rates (SVR 24: 90-100\%). Although no discontinuations due to adverse events were reported, serious adverse events were more frequent in the treatment arms receiving higher doses of asunaprevir (15\% vs. $5 \%$ ). ${ }^{38}$

\section{VX222/Telaprevir/PegIFN/RBV}

VX-222 is a nonnucleoside polymerase inhibitor, which targets thumb domain 2. In the ZENITH trial, VX-222, was studied as part of a QUAD therapy along with telaprevir (PI) and PegIFN/RBV. ${ }^{39}$ Fifty-nine treatment naïve, genotype 1 , noncirrhotic patients were randomized to receive telaprevir and VX-222 at $100 \mathrm{mg}$ or $400 \mathrm{mg}$ for 12 weeks along with PegIFN/RBV for 12 to 24 weeks based on response. One half of patients receiving the 400-mg dose were eligible for 12 weeks of therapy. At interim analysis, among patients eligible for 12 weeks of therapy, SVR12 was achieved in $82 \%$ of patients receiving low-dose VX-222 and 93\% of patients receiving the higher $400-\mathrm{mg}$ dose. Patients who required 24 weeks of therapy had similar response rates (SVR12: 83$87 \%)$. The most frequent adverse events reported included fatigue, rash, mild gastrointestinal symptoms, anemia, and pruritus. $^{39}$ 


\section{Tegobuvir/GS9451/PegIFN/RBV}

Tegobuvir is a nonnucleoside, palm domain 2 polymerase inhibitor that has demonstrated a mean reduction of $\mathrm{HCV}$ RNA of $1.5 \log 10 \mathrm{IU} / \mathrm{mL}$ in patients treated for 8 days of monotherapy. ${ }^{40}$ Investigators combined this agent with the PI GS-9451 along with PegIFN/RBV in an effort to shorten duration of therapy and improve efficacy. ${ }^{41}$ One-hundred nineteen noncirrhotic genotype 1 patients were treated with QUAD therapy for 16 to 24 weeks. Of these patients, $29 \%$ were IL28B genotype CC and $80 \%$ were genotype $1 \mathrm{a}$. In intention to treat analysis, patients treated with quadruple therapy had an SVR24 rate of 79\%. Notably, patients with genotype 1a subtype had inferior response rates when compared with genotype 1b (SVR24: 74\% vs. 90\%). Grade 3 adverse events were seen in $19 \%$ of patients treated with tegobuvir-based QUAD therapy and 29\% developed neutropenia defined as neutrophils $<750 / \mathrm{mm}^{3}$. ${ }^{41}$

\section{Conclusions}

Multiple DAAs in development show promise as effective treatment for HCV. Although IFN remains a backbone of many new regimens, the addition of these novel agents are likely to result in increased tolerability and efficacy when compared with the current standard of care. Interferon-free therapy may be available and effective for some, however, the use of IFN, especially when coadministered with multiple DAAs, may continue to be a necessity for many difficult to treat patients.

\section{Disclosures}

Andrew Aronsohn, MD: Nothing to disclose.

Donald Jensen, MD: Research grants: Abbvie, BoehringerIngelheim, BMS, Genentech, Gilead, Janssen. Consultations: Boehringer-Ingelheim, BMS, Idenix, Janssen

\section{References}

1 Jacobson IM, McHutchison JG, Dusheiko G, et al; ADVANCE Study Team. Telaprevir for previously untreated chronic hepatitis $C$ virus infection. N Engl J Med 2011;364(25):2405-2416

2 Poordad F, McCone J Jr, Bacon BR, et al; SPRINT-2 Investigators. Boceprevir for untreated chronic HCV genotype 1 infection. N Engl J Med 2011;364(13):1195-1206

3 Di Bisceglie A, Kuo A, Rustgi V, Sulkowski M. Virological outcomes and adherence to treatment algorithms in a longitudinal study of patients with chronic hepatitis $C$ treated with boceprevir or telaprevir in the U.S. (HCV-TARGET). Paper presented at: AASLD The Liver Meeting; November 1-5, 2013; Washington, DC

4 Brass V, Berke JM, Montserret R, Blum HE, Penin F, Moradpour D. Structural determinants for membrane association and dynamic organization of the hepatitis C virus NS3-4A complex. Proc Natl Acad Sci U S A 2008;105(38):14545-14550

5 Loo YM, Owen DM, Li K, et al. Viral and therapeutic control of IFNbeta promoter stimulator 1 during hepatitis $C$ virus infection. Proc Natl Acad Sci U S A 2006;103(15):6001-6006

6 Clark VC, Peter JA, Nelson DR. New therapeutic strategies in HCV: second-generation protease inhibitors. Liver Int 2013;33 (Suppl 1):80-84
7 Jacobson I, Dore G, Foster G, Fried M. Simeprevir (TMC435) with peginterferon/ribavirin for chronic hCV genotype 1 infection in treatment-naïve patients: results from QUEST-1, a Phase III trial. Paper presented at: The 48th Annual Meeting of the European Association for Study of the Liver Amsterdam; April 24-28, 2013; Amsterdam, The Netherlands

8 Olysio. Available at: http:www:olysio.com. Accessed February 9, 2014

9 Manns M, Marcellin P, Poordad F, Addonso de Araujo E. Simeprevir (TMC435) with peginterferon- $\alpha 2 \mathrm{a}$ or $-\alpha 2 \mathrm{~b}$ and ribavirin in treatment-naïve HCV genotype 1 patients: QUEST-2, a randomised phase III trial. Paper presented at: The 48th Annual Meeting of the European Association for Study of the Liver Amsterdam; April 2428, 2013; Amsterdam, The Netherlands

10 Zeuzem S, Berg T, Gane E, et al. Simeprevir increases rate of sustained virologic response among treatment-experienced patients with HCV genotype-1 infection: a Phase IIb trial. Gastroenterology 2014;146(2):430-, e6

11 Summa V, Ludmerer SW, McCauley JA, et al. MK-5172, a selective inhibitor of hepatitis C virus NS3/4a protease with broad activity across genotypes and resistant variants. Antimicrob Agents Chemother 2012;56(8):4161-4167

12 Manns M, Vierling J, Bacon B, Marcellin P. High sustained viral response of MK-5172 with pegylated interferon alfa-2b and ribavirin in HCV genotype 1 treatment-naive non-cirrhotic patients. Paper presented at: The 48th Annual Meeting of the European Association for Study of the Liver Amsterdam; April 2428, 2013; Amsterdam, The Netherlands

13 Bronowicki JP, Pol S, Thuluvath PJ, et al. Randomized study of asunaprevir plus pegylated interferon-. $\alpha$ and ribavirin for previously untreated genotype 1 chronic hepatitis C. Antivir Ther 2013; 18(7):885-893

14 Bronowicki JP, Ratziu V, Gadano A, Thuluvath PJ. Asunaprevir with peginterferon-alfa and ribavirin in treatment-naive patients with genotype-1 or -4 chronic hepatitis C: SVR24 results from a randomized phase 2b study (AI447-016). Paper presented at: The 48th Annual Meeting of the European Association for Study of the Liver Amsterdam; April 24-28, 2013; Amsterdam, The Netherlands

15 Sulkowski MS, Asselah T, Lalezari J, et al. Faldaprevir combined with pegylated interferon alfa-2a and ribavirin in treatment-naïve patients with chronic genotype $1 \mathrm{HCV}$ : SILEN-C1 trial. Hepatology 2013;57(6):2143-2154

16 Sulkowski MS, Bourlière M, Bronowicki JP, et al. Faldaprevir combined with peginterferon alfa-2a and ribavirin in chronic hepatitis $C$ virus genotype- 1 patients with prior nonresponse: SILEN-C2 trial. Hepatology 2013;57(6):2155-2163

17 Jensen D, Asselah TD. D., Foster GR. A pooled analysis of two randomized, double-blind placebo-controlled Phase III trials (STARTVerso1\&2) of faldaprevir plus pegylated interferon alfa$2 \mathrm{a}$ and ribavirin in treatment-naïve patients with chronic hepatitis C genotype-1 infection. Paper presented at: AASLD The Liver Meeting; November 1-5, 2013; Washington, DC

18 Jacobson I, Asselah T, Ferenci P, Foster G. STARTVerso3: A randomized, double-blind, placebo-controlled Phase III trial of faldaprevir in combination with pegylated interferon alfa-2a and ribavirin in treatment-experienced patients with chronic hepatitis $C$ genotype-1 infection. Paper presented at: AASLD The Liver Meeting; November 1-5, 2013; Washington, DC

19 Rockstroh J, Nelson M, Soriano V, Arasteh K. STARTVerso 4 Phase III trial of faldaprevir plus peg interferon alfa-2a and ribavirin (PR) in patients with HIV and HCV genotype 1 coinfection: end of treatment response. Paper presented at: AASLD The Liver Meeting; November 1-5, 2013; Washington, DC

20 Lee C. Daclatasvir: potential role in hepatitis C. Drug Des Devel Ther 2013;7:1223-1233 
21 Gao M, Nettles RE, Belema M, et al. Chemical genetics strategy identifies an HCV NS5A inhibitor with a potent clinical effect. Nature 2010;465(7294):96-100

22 Dore G, Lawitz E, Hezode C, Shafran SD. Daclatasvir combined with Peginterferon Alfa 2a Alfa-and Ribavirin for 12 or 16 Weeks in patients with hepatitis $C$ virus genotype 2 or 3 infection: COMMAND GT 2/3 study. Paper presented at: The 48th Annual Meeting of the European Association for Study of the Liver Amsterdam; April 24-28, 2013; Amsterdam, The Netherlands

23 Hezode C, Hirschfield GM, Ghesquiere W, Sievert W. Daclatasvir, an NS5A replication complex inhibitor, combined with peginterferon alfa-2a and ribavirin in treatment-naive HCV-genotype 1 or 4 patients: phase 2b COMMAND-1 SVR12 results. Paper presented at: AASLD The Liver Meeting; November 9-13, 2012; Boston, MA

24 Au JS, Pockros PJ. Novel therapeutic approaches for hepatitis C. Clin Pharmacol Ther 2013;95(1):78-88

25 Lawitz E, Rodriquez-Torres M, Rustgi V, Hassanein T. Safety and antiviral activity of ANA598 in combination with pegylated interferon $\alpha 2$ a plus ribavirin in treatment-naïve genotype- 1 chronic HCV patients. Paper presented at: The 48th Annual Meeting of the European Association for Study of the Liver Amsterdam; April 2428, 2013; Amsterdam, The Netherlands

26 Available at: A study of setrobuvir in combination with Pegasys (peginterferon alfa-2a) and Copegus (ribavirin) in patients with genotype 1 chronic hepatitis C. Available at: www.clinicaltrials. gov. Accessed December 27, 2013

27 Zeuzem S, Soriano V, Asselah T, et al. Faldaprevir and deleobuvir for HCV genotype 1 infection. N Engl J Med 2013;369(7):630-639

28 Larrey D, Lohse AW, de Ledinghen V, et al. Rapid and strong antiviral activity of the non-nucleosidic NS5B polymerase inhibitor BI 207127 in combination with peginterferon alfa 2a and ribavirin. J Hepatol 2012;57(1):39-46

29 Kowdley KV, Lawitz E, Crespo I, et al. Sofosbuvir with pegylated interferon alfa-2a and ribavirin for treatment-naive patients with hepatitis C genotype-1 infection (ATOMIC): an open-label, randomised, multicentre phase 2 trial. Lancet 2013;381(9883):2100-2107

30 Lawitz E, Lalezari JP, Hassanein T, et al. Sofosbuvir in combination with peginterferon alfa-2a and ribavirin for non-cirrhotic, treatment-naive patients with genotypes 1,2 , and 3 hepatitis $C$ infection: a randomised, double-blind, phase 2 trial. Lancet Infect Dis 2013;13(5):401-408

31 Lawitz E, Mangia A, Wyles D, et al. Sofosbuvir for previously untreated chronic hepatitis C infection. N Engl J Med 2013; 368(20):1878-1887

32 Wedemeyer $\mathrm{H}$, Jensen D, Herring R Jr, et al; PROPEL Investigators. PROPEL: a randomized trial of mericitabine plus peginterferon alpha-2a/ribavirin therapy in treatment-naïve HCV genotype $1 / 4$ patients. Hepatology 2013;58(2):524-537

33 Pockros PJ, Jensen D, Tsai N, et al; JUMP-C Investigators. JUMP-C: a randomized trial of mericitabine plus pegylated interferon alpha2a/ribavirin for 24 weeks in treatment-naïve HCV genotype 1/4 patients. Hepatology 2013;58(2):514-523

34 Feld J, Jacobson I, Jensen D, Foster G. Up to 100\% SVR4 rates with ritonavir-boosted danoprevir (DNVr), mericitabine and ribavirin with or without peginterferon alfa-2a (40KD) in HCV genotype 1infected partial and null responders: results from the MATTERHORN study. Paper presented at: AASLD The Liver Meeting; November 9-13, 2012; Boston, MA

35 ClinicalTrials.gov. A study of mericitabine in combination with telaprevir and Pegasys/Copegus in patients with chronic hepatitis C. Available at: http://clinicaltrials.gov/ct2/show/NCT01482390? term $=$ mericitabine\&rank=1. Accessed February 9, 2014

36 ClinicalTrials.gov. A study of mericitabine in combination with boceprevir and Pegasys/Copegus in patients with chronic hepatitis C. Available at: http://clinicaltrials.gov/ct2/show/NCT01482403? term $=$ mericitabine\&rank $=2$. Accessed February 9, 2014

37 Lok AS, Gardiner DF, Lawitz E, et al. Preliminary study of two antiviral agents for hepatitis C genotype 1. N Engl J Med 2012; 366(3):216-224

38 Lok AS, Hezode C, Lawitz E, Gardiner DF. Sustained virologic response in chronic HCV genotype (GT) 1-infected null responders with combination of daclatasvir (DCV; NS5A inhibitor) and asunaprevir (ASV; NS3 Inhibitor) with or without peginterferon alfa2a/ribavirin (PEG/RBV). Paper presented at: AASLD The Liver Meeting; November 9-13, 2012; Boston, MA

39 Gane E, Di Bisceglie A, Sulkowski M, Jacobson I. VX-222/telaprevir in combination with peginterferon-alfa-2a and ribavirin in treatment-naïve genotype $1 \mathrm{HCV}$ patients treated for 12 weeks: ZENITH study, SVR12 interim analysis. Paper presented at: The 22st Conference of the Asian Pacific Association for the Study of the Liver APASL February 16-19, 2012; Taipei, Taiwan

40 Zeuzem S, Buggisch P, Agarwal K, et al. The protease inhibitor, GS9256, and non-nucleoside polymerase inhibitor tegobuvir alone, with ribavirin, or pegylated interferon plus ribavirin in hepatitis $C$. Hepatology 2012;55(3):749-758

41 Pol S, Jablkowski M, Trenkle J, Kanwar B. Antiviral efficacy of the once daily NS3 protease inhibitor GS-9451, the non-nucleoside NS5B inhibitor tegobuvir (GS-9190), and pegylated interferon + ribavirin in treatment-naïve patients with genotype 1 hepatitis $C$ infection. Paper presented at: The 48th Annual Meeting of the European Association for Study of the Liver Amsterdam; April 2428, 2013; Amsterdam, The Netherlands 